\title{
Charting the Green and Climate-Adaptive City
}

The 'green city', with abundant vegetation, is an ideal with seemingly universal appeal, transcending temporal, spatial and cultural divides. Vegetated urban spaces, with diverse forms and contributing multiple functions, have been collectively termed 'green infrastructure'. These vegetated spaces include street trees, green alleys, greenways, green roofs, green walls, urban parks and informal green spaces (e.g. vacant lots). They may be created from scratch, modified from pre-urbanization natural bequest, generated on ruderal sites by spontaneous colonization, or inherited as remnant natural enclaves. Such greenery can enhance the liveability of cities by improving landscape and environmental quality, quality of life, and citizen health (Wolch et al., 2014).

Green infrastructure typically refers to an interconnected network of such multifunctional green-spaces, which is strategically planned and managed to provide a range of ecological, social, and economic benefits (Benedict and McMahon, 2006; Wright, 2011). Green infrastructural development has been driven by changes in local demand and urban form over time, but in the past decade it has attracted burgeoning interest, including notably its potential as a climate change intervention.

Global climate change poses new challenges and an additional raison d'être to optimize urban green-space planning and management (Douglas, 2011; Norton et al., 2015; Perry, 2015). Scientists anticipate warmer average temperatures, intensified storms and extreme weather conditions in the decades ahead. The Intergovernmental Panel on Climate Change (IPCC) has indicated a high possibility of surface air warming by more than $2{ }^{\circ} \mathrm{C}$ degrees in the $21^{\text {st }}$ century (IPCC, 2014). This will bring profound consequences for the global environment with aggravation in cities. For example, the urban heat island effect will increase the intensity and frequency of heat-waves - crippling essential infrastructure and increasing mortality and morbidity. Longer and more frequent episodes of urban climate shifting beyond the human comfort zone will beset inhabitants and increase energy consumption and attendant pollution impacts. Coupled with increasingly variable precipitation and gradual sea level rises, climate change is expected to bring significant impacts to urban populations. With more than half of humanity dwelling in cities, many of which are beset by chronic environmental and ecological stresses, urban populations are expected to suffer more from climate change impacts.

Green infrastructure constitutes a local response to the most pressing global challenge in our times. The varied sustainable ecosystem services delivered by urban greenery in a cost-effective and efficient manner can potentially shield cities against adverse effects of climate change. By harnessing and blending natural processes with conventional infrastructural development, green infrastructure can help moderate natural hazards, regulate water balance, and alleviate heat stress. It can strengthen 
the climate resilience of cities and their citizens. Recent research has suggested that green infrastructure should be systematically and synergistically integrated into urban climate change adaptation responses (Byrne and Yang, 2009; Gill et al., 2007).

This Special Issue offers a collection of research papers that cogently assess the role of green infrastructure in the climate change context. It presents a multidisciplinary project, which solicits and synthesizes new research findings from a breadth of cognate fields. This research effort is intended to build a solid foundation, enabling the development of cutting-edge knowledge and effective practices about the use of green infrastructure for climate change adaptation. The Special Issue includes nine contributions addressing some critical questions, how can urban green infrastructure help lessen climate change impacts on cities, what are the challenges and limitations of using urban green infrastructure, and how can planning and management options deliver the multiple benefits of green infrastructure and confer them upon urban residents?

The nine papers report cutting-edge research into urban green infrastructure from a wide range of disciplinary perspectives and geographical contexts. The Special Issue begins with three empirical studies that demonstrate the benefits of green cover for temperature moderation in different climatic zones. Jim (2015) assesses the thermal performance of rooftop vegetation, using data collected from a green roof site in Hong Kong, a subtropical compact city in Asia. Records on the cooling capacity of different vegetation species confirm that rooftop vegetation can reduce building temperatures and contribute to climate adaptation, despite some variations in their thermal-energy performance.

The study reported by Emmanuel and Loconsole (2015) is instrumental to estimating urban overheating problem and assessing the effectiveness of green infrastructure strategies in overcoming them. They note that a $20 \%$ increase in green cover could reduce surface temperature by $2^{\circ} \mathrm{C}$ by 2050 in Glasgow, Scotland and street users are likely to find such an increase in green cover thermally acceptable, even under a future warming scenario. Klemm et al. (2015) echo the Scottish study while turning our focus to Utrecht, the Netherlands, which has a maritime mild temperate climate. Their empirical study shows that street greenery can improve thermal comfort and that street users appreciate both the microclimatic and aesthetic benefits of street greenery. The new evidence provided by these authors, across different urban settings, affirms the value of urban green infrastructure in adapting cities to a warming climate.

The next three papers incorporate technical analyses with a more salient human dimension by focusing on thermal comfort and its implications for greenspace design. Abreu-Harbich et al. (2015) investigate tree canopy in Campinas, a subtropical city in Brazil. The quantitative research shows that thermal comfort can 
be greatly improved by planting tree species with small bipinnate linear leaves, plagiotropic trunks, large green coverage, and moderate crown permeability. Mazhar et al. (2015) offer equally valuable insights from a case study of open spaces in Lahore, Pakistan, which is known for its hot and semi-arid climate. They emphasize the importance of shade trees in intercepting solar radiation and their adaptation benefits for cities in the Middle East, which can experience very hot weather. Based on a comprehensive study of five climate zones around the world, Brown et al. (2015) suggest that urban planners and park designers should give preference to a tree canopy cover to block out penetrating solar radiation and the same time offer evaporative cooling, and focus on developing shaded green-space. These contributions clearly indicate the positive implications of urban green infrastructure for regulating the physical climate as well as improving the well-being of humans.

Human dimensions are further advanced by Byrne et al. (2015), who investigate the ways in which residents of Hangzhou, China perceive and evaluate the contributions of tree planting to mitigate climate change impacts on the city. Their findings confirm that Hangzhou green-space users widely accept the benefits of urban greening. They identify the conditions that enhance public recognition of tree planting. Importantly, they indicate the pressing need for directing more efforts towards communicating the benefits of green-infrastructure to senior citizens in particular, in order to improve acceptance of this adaptive response. Urban planners in China, and internationally, are urged to more effectively include public involvement into the process of green-space planning and management, to improve the prospects for a societally-relevant green-infrastructural response to climate change.

The Special Issue concludes with discussions on planning issues, integrating human with policy dimensions. The final set of papers is produced by two different research groups. Vollmer et al. (2015) assess the cultural value of a river corridor in Jakarta, Indonesia, and explain its implications for planning. Using a mixed-method approach, they solicit local residents' preferences for the services that the river delivers and future changes to the riparian site. Demonstrating the social benefits of the riverfront to local communities is important, because this can strengthen the case for conservation in situ and for continually making the riverfront available to local residents. Like Byrne et al. (2015), Vollmer et al. conclude that giving local residents greater access to the green spaces around the river will be important for them to adapt to the increasing heat stress caused by climate change. Urban planners and decision-makers are encouraged to take this into account when evaluating the contributions of urban green infrastructure.

In the concluding paper of the Special Issue, Matthews et al. (2015) identify a number of unaddressed institutional barriers to planning green infrastructure for climate change adaptation when a greater degree of cross-sector and cross- 
departmental coordination is required. This paper raises concerns about advocating urban green infrastructure benefits without addressing the associated tensions and potential drawbacks in practice. Matthews et al. respond to the fundamental question about the definition of urban green infrastructure and propose a conceptual framework for promoting better understanding of this area of research.

The collection of high-quality papers in this Special Issue addresses the relationship between urban green infrastructure and climate change, and articulates the challenges and possible solutions. Together, these papers cover three main themes pertaining to: the physical capacity for adaptation, designing green spaces for urban populations, and institutionalizing and mainstreaming adaptation in green infrastructural planning. There is a clear consensus that urban green infrastructure can play an important role in insulating cities from climate change impacts. Yet the complexities involved in climate change issues create enormous challenges for decision-makers. Researchers have consistently demonstrated how green infrastructure can increase the adaptive capacity of cities with different physical constraints and in different geographical locations. They also point to the need for clearer understandings of the concept of green infrastructure and more effective ways for coordinating diverse planning and management actions in deploying green infrastructure.

This collection of papers offers a balance of scientific and policy-relevant insights, and affirms the value of multi-disciplinary inputs from urban ecologists, engineers, plant scientists, urban planners, geographers, economists and practitioners. There is a burgeoning interest in the topic of green infrastructure, and this Special Issue has highlighted some knowledge gaps that warrant urgent and more sophisticated attention. Importantly, we need more rigorous scientific investigations into the costs, not just the benefits of green infrastructure. Are there places where the use of green infrastructure would be inappropriate, for health and safety reasons, for the protection of cultural heritage, or due to financial limitations? Could some practices of urban green infrastructure installation and management exacerbate climate change - for example through mechanised tree planting, the composting of green-waste, or depleting water resources? How might the climate mitigation costs and benefits of urban green infrastructure be identified, measured and quantified in a more rigorous way and across different spatiotemporal scales?

We also need research into what some may call the 'political economy' or 'political ecology' of urban green infrastructure, to fill knowledge gaps in the human dimensions of urban green infrastructure. For example, how do constellations of actors shape the landscapes of urban green infrastructure decision-making across local, regional, national, and even international levels? Are there potential problems associated with environmental injustice (e.g. is access to green infrastructure differentiated by race, ethnicity, class, disability etc.)? Could widespread uptake of 
urban green infrastructure increase human-wildlife conflict in cities (e.g. providing roosts for colonies of fruit bats thus threatening neighbourhood amenity)? What measures are being taken to ensure that appropriate species are chosen to minimise damage to other forms of infrastructure (e.g. underground pipes, telecommunications and drainage) or harm to human health (e.g. increased asthma from pollen) or property (e.g. damage from wildfire)? And what are the insurancerelated issues associated with urban green infrastructure (e.g. damage from windthrow)?

Further joint efforts are needed in meeting the conceptual and practical trials that lie ahead. 


\section{References}

Abreu-Harbich, L. V., Labaki, L. C., Matzarakis, A., 2015, Effect of tree planting design and tree species on human thermal comfort in the tropics, Landscape and Urban Planning this volume/issue.

Brown, R., Vanos, J. K., Kenny, N. A., Lenzholzer, S., 2015, Designing Urban Parks That Ameliorate the Effects of Climate Change, Landscape and Urban Planning this volume/issue.

Byrne, J., Lo, A. Y., Yang, J., 2015, Residents understanding of the role of green infrastructure for climate change adaptation in Hangzhou, China, Landscape and Urban Planning this volume/issue.

Byrne, J. A., Yang, J., 2009, Can urban greenspace combat climate change? Towards a subtropical cities research agenda, Australian Planner 46(4):36-43.

Douglas, I., 2011, The role of green infrastructure in adapting cities to climate change, in: Handbook of Urban Ecology (I. Douglas, D. Goode, M. Houck, eds.), Routledge, Florence, KY.

Emmanuel, R., Loconsole, A., 2015, Green infrastructure as an adaptation approach to tackle urban overheating in the Glasgow Clyde Valley Region, Landscape and Urban Planning this volume/issue.

Gill, S. E., Handley, J. F., Ennos, A. R., Pauleit, S., 2007, Adapting Cities for Climate Change: The Role of the Green Infrastructure, Built Environment 33(1):115133.

Intergovernmental Panel on Climate Change (IPCC), 2014, Climate Change 2013: The Physical Science Basis: Working Group I Contribution to the Fifth Assessment Report of the Intergovernmental Panel on Climate Change, New York, Cambridge University Press.

Jim, C. Y., 2015, Assessing climate-adaptation effect of extensive tropical green roofs in cities, Landscape and Urban Planning this volume/issue.

Klemm, W., Heusinkveld, B. G., Lenzholzer, S., Van Hove, B., 2015, Street greenery and its physical and psychological impact on outdoor thermal comfort, Landscape and Urban Planning this volume/issue.

Matthews, T., Lo, A. Y., Byrne, J., 2015, Reconceptualizing green infrastructure for climate change adaptation: Barriers to adoption and drivers for uptake by spatial planners, Landscape and Urban Planning this volume/issue.

Mazhar, N., Brown, R., Kenny, N., Lenzholzer, S., 2015, Thermal comfort of outdoor spaces in Lahore Pakistan: Lessons for bioclimatic urban design in the context of global climate change, Landscape and Urban Planning this volume/issue.

Norton, B. A., Coutts, A. M., Livesley, S. J., Harris, R. J., Hunter, A. M., Williams, N. S. G., 2015, Planning for cooler cities: A framework to prioritise green infrastructure to mitigate high temperatures in urban landscapes, Landscape and Urban Planning 134(0):127-138.

Perry, J., 2015, Climate change adaptation in the world's best places: A wicked problem in need of immediate attention, Landscape and Urban Planning 133(0):1-11.

Vollmer, D., Prescott, M. F., Padawangi, R., Girot, C., Grêt-Regamey, A., 2015, Understanding the value of urban riparian corridors: Considerations in 
planning for cultural services along an Indonesian river, Landscape and Urban Planning this volume/issue.

Wolch, J. R., Byrne, J., Newell, J. P., 2014, Urban green space, public health, and environmental justice: The challenge of making cities 'just green enough', Landscape and Urban Planning 125(0):234-244. 